\title{
Speculative Oceanography: An Historical Survey of the Literature
}

\author{
Dr Jim Clarke* \\ School of Humanities, Coventry University, UK
}

*Corresponding author: Dr Jim Clarke, Coventry University, Priory Street, Coventry, UK.

Received Date: May 12, 2020

Published Date: May 22, 2020

\begin{abstract}
As a fundamentally interdisciplinary sector of study, oceanography spans not only the physical and chemical attributes of large saline aquatic environments, but also overlaps with biological considerations of oceanic flora and fauna, and incorporates a wide variety of sub-topics, from orbital wave dynamics, to plate tectonics, to acoustic oceanography. As a major component of the planetary surface, oceans therefore additionally form a significant component of Earth Science study, particularly in an era of ongoing and accelerating climate change. However, one interdisciplinary intersection which has largely been hitherto underexplored is that of oceanography's overlap with the speculative arts, a subset which might be termed speculative oceanography. This paper intends to address this gap in research by collating and reprising existing speculative oceanography, in order to identify and codify the broad areas of interest and future study which arise there from. One such area identified, which explores the oceanographic properties of non-terrestrial large aquatic bodies, is herein termed exo-oceanography, for example. The paper concludes with a call for greater interdisciplinary co-operation between oceanographic researchers and speculation methodologies.
\end{abstract}

Keywords: Speculative Oceanography; Crypto-hominids; Exo-oceanography; Malevolent Aquatic Megafauna; Oceanic Sentience

\section{Introduction}

The parameters of oceanography are perpetually expanding as our technological capacity to access and comprehend what were once intimidating and unmappable bodies has increased. The discipline now extends far and wide, utilizing a range of methodological practices borrowed from the hard sciences, biology, geography, climate science and social science in a genuinely multidisciplinary framework. Nevertheless, the application of speculative methodological practice has to date been under examined and underutilized. In an era of climate change and significant aqua-fauna extinction, it is ever more pressing that a speculative approach to oceanographic practices is utilized. This paper, building on methodological practices of pioneers in the field of meta-epistemological inquiry such as Sokal [1] , Sokal and Bricmont [2] ,Miller et. al. [3] , Miller [4] , Miller [5] Wilson [6] , Baldwin [7] , Baldwin [8] and Smith [9] , while also extending previous research by Clarke [10] , Clarke [11] , Clarke [12] , Clarke
[13] and Vincent \& Clarke [14], aims to reinstate that gap in the knowledge. Speculative practices about oceanography likely date back at least as far as early human maritime transport, and certainly can be noted in Roman inquiries, such as that conducted by Avienus [15] in the 4th century CE, in which he drew upon the now lost Massiliote Periplus to review the navigations of the Carthaginian Himlico from some nine centuries earlier. Avienus [15], and presumably the lost research upon which he had based his work, identified by speculation the likely existence of malevolent subaquatic megafauna, which was later again described in the Irish Navigatio Sancti Brendani Abbatis and other immram texts of the eighth century CE , and persisted in the literature of explorers from England, Holland, Spain and many indigenous cultures of Africa, Asia and the Americas as reported by the Belgian zoologist Bernard Heuvelmans [16] and others, right up to the late 19th century. The subject of non-indigenous subaquatic megafauna was extensively studied in the 1950s by Professor Alastair Bocker in relation to 
their relationship with rising ocean levels and their ultimate vulnerability to ultrasonic weaponry. This phylum of research was not restricted to aquatic megafauna study however. In many North Atlantic locations, including Iceland, the Faroes, Ireland and particularly the Scottish islands, identification and classification of aquatic crypto-hominids, in particular homo halichoerus, or the common selkie, was widespread for centuries. However, the most recent field report [17] emanates from America, but may relate to a colony originally found in Norway. The female homo halichoerus was much more regularly observed, in keeping with sightings of other aquatic hominids, such as the widely distributed homo pisces, which has been observed globally in locations such as Southern Africa, East Asia, the Mediterranean basin and the Caribbean. Similar crypto-hominids, such as the Chinese jiaoren, may well form their own taxonomical classification as homo carcharodon, though other cryptobiologists consider these to be simply a regional variant form of homo pisces. The most recent substantial observation of any homo pisces variant is the Massachussets mass sighting by Olmstead, as recorded by Lovecraft in [18]. Despite the sheer volume of cryptozoological evidence in data from before Roman times, and from almost every continent, the advent of submarine transportation, trans-oceanic transport via steam, sonar and a range of other scientific methodologies led to the emergence of an exclusively empiricist approach to the burgeoning discipline of oceanography from the late 19th century onwards. However, this abandoning of the speculative model in relation to the study of terrestrial oceans was not necessarily consistently followed in relation to non-terrestrial bodies of water, a field we may describe as exo-oceanography or astro-oceanography. The early identification of the lunar maria by Apuleius in the 2nd century CE is indicative of this, and it was a trend which persisted. Indeed, though Giovanni Schiaparelli's much cited study of Martian canali was predominantly derived from empirical astronomical observations conducted by telescope, its subsequent interpretation as canals, and the derived conclusions about Martian civilisation, was the product of purely speculative methods conducted chiefly by the American astronomer Percival Lowell among others. There is, therefore, from the late 19th century onwards, a range of methodological approaches to oceanography and cognate disciplines, ranging from the purely empiricist, via hybrid models such as Lowell demonstrated, to the purely speculative. Notably, Lowell's conclusions were challenged not only by empirical researchers but also by the speculative scientist PK Dick [19]. However, non-empirical approaches tended to predominate, especially in the exploration of non-terrestrial oceans in work by Anderson and Vance [20,21]. Of particular note in this context is the burgeoning study of Venusian oceanography in the research of French and Zelazny. The particular intersection of astrobiology and oceanography was pursued predominantly within the Soviet bloc in the mid-20th century, and Lem's work in particular on sentient astrobiological ocean-sized lifeforms, later developed and documented on film by Tarkovskiy [22], was only belatedly acknowledged by the West in 2002. It is likely that Lem's work influenced the Federation encounter with the Monean Maritime Sovereignty, first reported in 1998 [23], and almost certainly informed the Federation's discovery of the Dominion Founders' homeworld, an M-class rogue planet located within the Omarion Nebula in the Gamma Quadrant, as first reported in 1994 [24]. More recently, Kemp has reported another case of non-terrestrial oceanic sentience, while Reynolds [25] and [26] has produced studies of sentient aquatic micro-organism groups in a number of non-terrestrial oceanic settings. While few incidences of terrestrial oceanic sentience have been reported in the modern era, they were plentiful in ancient times, perhaps indicating an extinction event at some time during early recorded history. In contrast to this, a hypothesis of ongoing terrestrial oceanic sentience may be extrapolated from a broad interpretation of the research of Lovelock and Margulis [27]. Attempts to create non- aquatic biota in the Atlantic region significantly predated this, though they were predicated upon technological adaptation to sub-aquatic environments by land-dwelling hominids, in this case homo sapiens rather than crypto-hominids. One notable example is the post-war development of the Rapture city by (construction completed in 1951), at an underwater location at $63^{\circ} 2^{\prime} \mathrm{N}, 29^{\circ} 55^{\prime} \mathrm{W}$, approximately 433 kilometers west of Reykjavik. However, the Rapture living experiment was largely destroyed by internal conflict issues in early 1959. Earlier attempts to institute fully sub-aquatic hominid living environments had previously been recorded by Blish [28] and [29]. In non-terrestrial contexts, entirely aquatic inhabitable extraterrestrial bodies have been posited by both Shaw [30] and Banks [31] among others. Clarke [32] , and later Clarke andLee [33] , [34] , and [35] , have additionally reported a case of a non-terrestrial attempt to circumscribe a non-sentient ocean within a transport vehicle in a series of related studies. Speculative examination has furthermore determined the existence of nonwater based oceans, complementing similar empirical research. Just as the Juno project led by NASA's Jet Propulsion Laboratory has established the existence of a hydrogen ocean on the surface of Jupiter - likely the largest ocean of any kind in the solar system - so hypertext speculators Kevin L Donihe and Carlton Mellick [36] III have posited the existence of an ocean of blubbery matter located in central Wyoming, USA. Among the most promising of recent speculative oceanographic research is the detailed first contact account of Dr Adaora, a marine biologist at the University of Lagos, and Mills' description of an oceanic temporal flux phenomenon identified at Candorrea. Though temporal variation in water currents and aquafauna have been empirically examined in relation to terrestrial oceans, the possibility of the oceans generating temporal shifts has yet to be fully examined. In a paper such as this, it is barely possible to dip a toe in the extensive sea of speculative discoveries which could impact on the field of oceanography. In conclusion, speculative oceanography offers a wide range of potential topics likely to open up the field to new interdisciplinary ways of considering the oceans, their activities and the life they 
contain. From aquatic megafauna, to crypto-hominids, exooceanography, oceanic sentience, sub-aquatic colonisation, nonwater ocean environments and oceanic temporal flux, speculative oceanography has the potential to plunge our understandings of the oceans to new and exciting depths [37-46].

\section{Acknowledgement}

The author would like to thank his colleague Dr Simon Smith for his encouragement in the production of this research, and wishes to acknowledge the particular assistance of Dr Joseph Walton of the University of Sussex, as well as the members of the LSFRC in London.

\section{Conflict of Interest}

No conflict of interest.

\section{References}

1. Alan D Sokal (1996) Transgressing the Boundaries: Toward a Transformative Hermeneutics of Quantum Gravity. Social Text 46-47: 217-252.

2. Alan D Sokal, Jean Bricmont (1997) Impostures intellectuelles. Paris: Editions Odile Jacob.

3. Joseph Miller, Anna LeMonte, Moses Templeton (2017) The Effect of Membrane Sweeping on Prelabor Rupture of Geese: A Randomized Controlled Trial. J Clin. Ob. Gyn. Inf. 1(5): 1024.

4. Joseph Miller (2018) Protozoal Importunity in a Thirty-Three-Year-Old Lawyer: A Farewell to Arms. Glob J Reprod Med 5(1): 555652.

5. Joseph Miller (2019) Unrelenting Gynecological Conflict: Isn't It Time We All Got Along.J Womens Health Gyn 6: 1-3.

6. Helen Wilson (2018) Human reactions to rape culture and queer performativity at urban dog parks in Portland, Oregon. Gender, Place \& Culture 1-20.

7. Richard Baldwin (2018a) Who Are They to Judge? Overcoming Anthropometry and a Framework for Fat Bodybuilding. Fat Studies 7 (3): i-xiii.

8. Richard Baldwin (2018b) An Ethnography of Breastaurant Masculinity: Themes of Objectification, Sexual Conquest, Male Control, and Masculine Toughness in a Sexually Objectifying Restaurant. Sex Roles 79 (11-12): 762.

9. M Smith (2018) Going in Through the Back Door: Challenging Straight Male Homohysteria and Transphobia through Receptive Penetrative Sex Toy Use. Sexuality \& Culture 22 (4): 1542.

10. Jim Clarke (2013) Reading Climate Change in J.G. Ballard. Critical Survey 25(2): 7-21.

11.Jim Clarke (2018) The Aesthetics of Anthony Burgess: Fire of Words. London: Palgrave Macmillan.

12. Jim Clarke (2019a) Science Fiction and Catholicism: The Rise and Fall of the Robot Papacy. Canterbury: Gylphi.

13. Jim Clarke (2019b) Rope. Tree. Journalist. Some Assembly Required. Donald Trump's War on Journalism."Trumping Truth: Essays on the Destructive Power of 'Alternative Facts', ed Salvador Murguia.Bethlehem, PA: Lehigh University Press.

14. Benet Vincent, Jim Clarke (2017) The language of A Clockwork Orange: A corpus stylistic approach to Nadsat. Language and Literature 26(3): $247-264$
15. Postumius Rufus Festus Avienus (1977) Ora Maritima, trans. John P. Murphy. Chicago: Ares Publishing. 117-129.

16. Bernard Heuvelmans (1965) Le Grand-Serpent-de-Mer, le problème zoologique et sa solution. Paris: Plon.

17. Samatar (2013) Selkie Stories Are for Losers. Strange Horizons.

18. Lovecraft HP (1936) The Shadow Over Innsmouth. Everett, PA: Visionary Publishing.

19. Dick PK (1964) Martian Time-Slip. New York: Ballantine.

20. Poul Anderson (1958) The Game of Glory. Venture.

21. Jack Vance (1955) The Gift of Gab. Astounding.

22. Andrei Tarkovskiy dir (1972) Солярис. Moscow: Mosfilm.

23. Winrich Kolbe dir (1998) Thirty Days. Star Trek Voyager, Episode 5x09. First aired: 9th December 1998.

24. Kim Friedman dir (1994) The Search, Part I. Star Trek Deep Space 9, Episode 3x01. First aired.

25. Alastair Reynolds (2000) Revelation Space.London: Gollancz.

26. Alastair Reynolds (2003) Diamond Dogs, Turquose Days.London: Gollancz.

27. Lovelock JE, Margulis L (1974) Atmospheric homeostasis by and for the biosphere: the Gaia hypothesis. Tellus. Series A. Stockholm: International Meteorological Institute. 26 (1-2): 2-10.

28. James Blish (1942) Sunken Universe. Super Science Stories.

29. James Blish (1952) Surface Tension. Galaxy.

30. Bob Shaw (1977) Medusa's Children.London: Gollancz.

31. Iain M Banks (2004) The Algebraist.London: Orbit.

32. Arthur C Clarke (1973) Rendezvous with Rama. London: Gollancz.

33. Arthur C Clarke, Gentry Lee (1989)Rama II.London: Gollancz.

34. Arthur C Clarke, Gentry Lee (1991) The Garden of Rama. London: Gollancz.

35. Arthur C Clarke, Gentry Lee (1993) Rama Revealed. London: Gollancz.

36. Kevin L Donihe, Carlton Mellick (2005) Ocean of Lard. Portland OR: Eraserhead Press.

37. Samantha Mills (2018) Strange Waters. Strange Horizons.

38. Jonathan M, Wooding (2011) The date of 'Nauigatio S. Brendani abbatis. Studia Hibernica 37: 9-26

39. John Wyndham (1953) The Kraken Wakes. London: Michael Joseph.

40. Schiaparelli GV (1861-1900) Le Mani su Marte: I diari di GV Schiaparelli. Observational diaries, manuscripts \& drawings. Historical Archive of Brera Observatory.

41. Paul French (Isaac Asimov) (1954) Lucky Starr and the Oceans of Venus. New York: Ballantine.

42. Roger Zelazny (1965) The Doors of His Face, the Lamps of His Mouth. Magazine of Fantasy and Science Fiction.

43. Stanislaw Lem (1962) Solaris, Warsaw: MON.

44. Juliet Kemp (2018) A Glimmer of Silver. London: Book Smugglers Publishing.

45. John Shirley (2011) Bioshock: Rapture. New York: Tor.

46. Nnedi Okorafor (2014) Lagoon, London: Hodder and Stoughton. 